\title{
Evaluation of Intravitreal Aflibercept Injection for Macular Edema Secondary to Retinal Vein Occlusion
}

\author{
Emad Abdel Aal Saliem \\ Lecturer of Ophthalmology, Ophthalmology Department, Al-Azher Faculty of Medicine, Assuit \\ E-mail: emadophtha@yahoo.com.
}

\begin{abstract}
Background: To evaluate the efficacy of intravitreal aflibercept injection in eyes with macular edema due to retinal vein occlusion (RVO). Patients and Methods: prospective, non-randomized clinical study included 60 eyes of 60 patients with macular edema due to RVO. Thirty patients had branch RVO (BRVO) and 30 had central RVO (CRVO). Each patient had received intravitreal injection of aflibercept once followed by re-evaluation of BCVA and CMT monthly during the follow up period up to 6 months after injection. Results: One month after IV aflibercept injection in patients with RVO $\leq 3$ months, the main best-corrected visual acuity improved from $1.05 \pm 0.004 \mu \mathrm{m}$ at baseline to $0.75 \pm 0.07 \log$ MAR at 1 month, to $0.58 \pm 0.10 \log$ MAR at $3^{\text {rd }}$ month and at the 6th month improved to $0.45 \pm 0.14 \operatorname{logMAR}(\mathrm{p} \leq 0.05)$. On the other hand, the mean BCVA improved from $1.40 \pm 0.03 \mu \mathrm{m}$ at baseline to $1.13 \pm 0.07 \log$ MAR at 1 month, to $0.98 \pm 0.06 \log$ MAR at $3^{\text {rd }}$ month and to $0.92 \pm 0.08$ $\log$ MAR at $6^{\text {th }}$ month $(P \leq 0.05)$ in patients with RVO $>3$ months. The mean central macular thickness reduced from $485.57 \pm 71.51 \mu \mathrm{m}$ at baseline to $316.78 \pm 58.38 \mu \mathrm{m} \quad(\mathrm{P} \leq 0.05)$ after 1 month, to $259.45 \pm 50.84 \mu \mathrm{m}(\mathrm{P} \leq 0.05)$ at the $3^{\text {rd }}$ month and to $225.85 \pm 34.44 \mu \mathrm{m}(\mathrm{P} \leq 0.05)$ at $6^{\text {th }}$ month in patients with $\mathrm{RVO} \leq 3$ months. Meanwhile, in those with RVO $>3$ months the main CMT reduced from baseline $625.91 \pm 167.56 \mu \mathrm{m}$ to $395.07 \pm 98.89 \mu \mathrm{m}(\mathrm{P} \leq 0.05)$, to $319.53 \pm 53.28 \mu \mathrm{m}(\mathrm{P} \leq 0.05)$ and at the 6 th month reduced to $276.50 \pm 38.89 \mu \mathrm{m}(\mathrm{p} \leq 0.05)$. No intra-operative or post-operative complications as retinal detachment, vitreous hemorrhage, or elevated intraocular pressure. Subconjunctival hemorrhage or local hyperemia at the injection site may be observed in some cases. Long term duration without treatment is associated with less improvement in the visual acuity. Conclusion: Intravitreal injection of aflibercept is more clinically effective and generally well tolerated for treatment of macular edema due to RVO.
\end{abstract}

Key words: Aflibercept, RVO, ME.

\section{INTRODUCTION}

Retinal vein occlusion (RVO) is a common sight-threatening vascular disorder of the retina, in which macular edema is the main cause of visual impairment ${ }^{[1]}$. It may involve the central (CRVO) or a branch (BRVO) retinal vein, which may be caused by a compression by adjacent atherosclerotic retinal arteries [2]. Retinal ischemia following vascular occlusion can cause both vitreous and aqueous vascular endothelial growth factor (VEGF) elevation ${ }^{[3]}$. Thrombosis of the retinal veins causes an increase in retinal capillary pressure resulting in increased capillary permeability and leakage of fluid and blood into the retina. Increased production of vascular endothelial growth factor (VEGF) occurring early in RVO is a major contributor to the evolution and persistence of ME and hemorrhages [4]. In addition, the high levels of VEGF promote the progression of retinal non perfusion and ischemia, which may in turn increase the levels of VEGF, hence exacerbating ME and hemorrhages leading to visual impairment ${ }^{[5,6]}$. Not all people with CRVO will require treatment and macular edema will resolve in about a third of those with non-ischaemic CRVO. However, most will need treatment and the number of options has increased in recent years [7]. For many years, laser photocoagulation has been the standard therapy for patients with macular edema secondary to branch retinal vein obstruction (BRVO) ${ }^{[8]}$. However, laser treatment was not found to be beneficial to those with macular edema secondary to CRVO, for these patients, no therapeutic modalities could be offered ${ }^{[9]}$.

Recently, several studies have demonstrated the benefit of anti-vascular endothelial growth factor (VEGF) therapies and steroids for the management of patients with 
macular edema secondary to CRVO ${ }^{[10]}$. Intravitreal injections of anti-VEGF, such as bevacizumab (Avastin ${ }^{\mathrm{TM}}$, Genentech Inc., South San Francisco, CA, USA) and aflibercept (Eylea $^{\mathrm{TM}}$, Regeneron Pharmaceuticals, Inc., Tarrytown, NY, USA, and Bayer Pharma AG, Berlin, Germany), can effectively reduce the intraocular level of VEGF and hence, reduce the vascular permeability related to macular edema in RVO ${ }^{[6]}$. Aflibercept (Eylea ${ }^{\circledR}$, Regeneron, Tarrytown, NY, USA) is the newest anti-VEGF drug that has been approved for the treatment of macular edema due to RVO. This recombinant fusion protein, composed of extracytoplasmic, native-receptor VEGF-binding sequences from

VEGF receptor (VEGFR)1 and VEGFR2 ${ }^{[11]}$, binds VEGF165 100 times tighter than either bevacizumab or ranibizumab, and also binds isoforms of VEGF-B and placental growth factor ${ }^{[12]}$. The VIBRANT trial demonstrated that aflibercept was superior to laser photocoagulation in eyes with BRVO ${ }^{[6]}$, and the COPERNICUS and GALILEO trials showed that aflibercept was superior to sham in eyes with CRVO ${ }^{[13,14]}$.

The most common side effects reported in patients receiving EYLEA are increased redness in the eye, eye pain, cataract, moving spots in the field of vision, increased pressure in the eye, and vitreous (gel-like substance) detachment.

\section{PATIENTS \& METHODS}

This prospective, non-randomized clinical study was performed at Al- Azher University Hospitals and included 60 eyes of 60 patients with macular edema secondary to RVO for the first time. Thirty patients had branch RVO (BRVO) and 30 had central RVO (CRVO). Only one eye from each patient was included in this study. Their ages range from $45 y_{\mathrm{s}}$ to $71 y_{\mathrm{s}}$ with the mean of age $56.3 \pm 8.15 \mathrm{yrs}$. Forty six eyes were phakic \& 14 were pseudophakic before injection. The majority of patients $(70 \%)$ known to be hypertensives and controlled by medical treatment. The study was approved by the Ethics Board of AlAzhar University.

\section{Exclusion criteria included}

(1) Patients with macular edema from causes other than RVO.

(2) Diminution in visual acuity from causes other than RVO.
(3) Any history of trauma, previous intravitreal injections, vitreo-retinal surgeries, retinal or macular laser.

(4) Ocular inflammation in one or both eyes.

(5) Uncontrolled glaucoma.

Macular edema can be defined as macular leakage on fundus fluorescein angiography and central macular thickness (CMT) more than $250 \mu \mathrm{m}$ detected by optical coherence tomography. All the patients were subjected to complete preoperative ophthalmic assessment; detailed history including the age, sex and duration of symptoms, best corrected visual acuity for near and distance, intraocular pressure measurement with applanation tonometry, slit-lamp examination of the anterior segment, indirect ophthalmoscopy, fundus fluorescein angiography (FFA), and optical coherence tomography (OCT) were done to all patients. Once the diagnosis had been confirmed, and after detailed explanation of risks and benefits of these medications, all the patients signed an informed consents before injection. After instillation of topical anesthesia and povidone-iodine solution onto the conjunctiva, a sterile retractor of eyelid was applied, aflibercept $(2 \mathrm{mg} / 0.05 \mathrm{ml})$ was injected through the sclera $(3.5-4 \mathrm{~mm}$ posterior to the limbus) into the mid-vitreous. After injection, antibiotic drop and ointment were applied to the conjunctival sac and the eye bandaged for 1 day, then the patient was adviced to instill one drop of an antibiotic into the injected eye four times daily for one week after injection.

All patients were followed up monthly during the follow up period for at least 6 months after injection. Follow up was scheduled as follows: $1^{\text {st }}$ month, $3^{\text {rd }}$ month and $6^{\text {th }}$ month.

At every visit the following items should be assessed.

- Best corrected visual acuity.

- Anterior segment examination.

- Assessment of IOP by applanation tonometry.

- Fundus examination.

- Fundus fluorescein angiography at the $3^{\text {rd }}$ and the $6^{\text {th }}$ months.

- OCT images were also taken at the $1^{\text {st }}$, $3^{\text {rd }}$ and the $6^{\text {th }}$ month to assess the central macular thickness.

Further injections may be needed if:

a) The BCVA got worse or

b) The CMT more than $250 \mu \mathrm{m}$ or 
c) There was sub-retinal fluid affecting the visual outcome even if CMT is less than $250 \mu \mathrm{m}$.

\section{Statistical analysis}

Statistical analysis were performed using SPSS version 22 (IBM Corporation, Chicago, IL, USA) Snellen BCVA values were converted into LogMAR for statistical analysis. Mean and Standard deviation were estimated. CMT and BCVA were assessed with the ANOVA test followed by tukey test and Pvalues of $<0.05$ were considered statistically significant.

\section{RESULTS}

Sixty eyes of 60 patients were enrolled in this study. Patients were equally divided; 30 patients had branch RVO (BRVO) and other 30 had central RVO (CRVO). The demographic data of patients revealed that 44 patients
(73.3\%) were males and $16(26.7 \%)$ were females. Age of patients included ranged from $45 y_{s}$ to $71 y_{s}$, with the mean age of $56.3 \pm 8.15$ yrs. Only one eye of each patient was included in this study. There were no statistically significant differences regarding the age, gender, lens status, laterality. One month after IV aflibercept injection in patients with $\mathrm{RVO} \leq$ 3 months, the main best-corrected visual acuity improved from $1.05 \pm 0.004 \mu \mathrm{m}$ at baseline to $0.75 \pm 0.07 \log$ MAR at 1 month, to $0.58 \pm 0.10 \log$ MAR at $3^{\text {rd }}$ month and by the end of 6th month improved to $0.45 \pm 0.14 \log$ MAR $(p \leq 0.05)$. On the other hand, the mean BCVA improved from $1.40 \pm 0.03 \mu \mathrm{m}$ at baseline to $1.13 \pm 0.07 \log$ MAR at 1 month, to $0.98 \pm 0.06$ $\log$ MAR at $3^{\text {rd }}$ month and to $0.92 \pm 0.08$ $\log$ MAR at $6^{\text {th }}$ month $(P \leq 0.05)$ in patients with $\mathrm{RVO}>3$ months (table 1and figure 1 ).

Table (1): The mean BCVA at base line and after $1^{\text {st }}, 3^{\text {rd }}, 6^{\text {th }}$ months of aflipercept injection in patients with RVO.

*cells in rows with different letter were significant differences at $\mathrm{p} \leq 0.05$ (LSD).

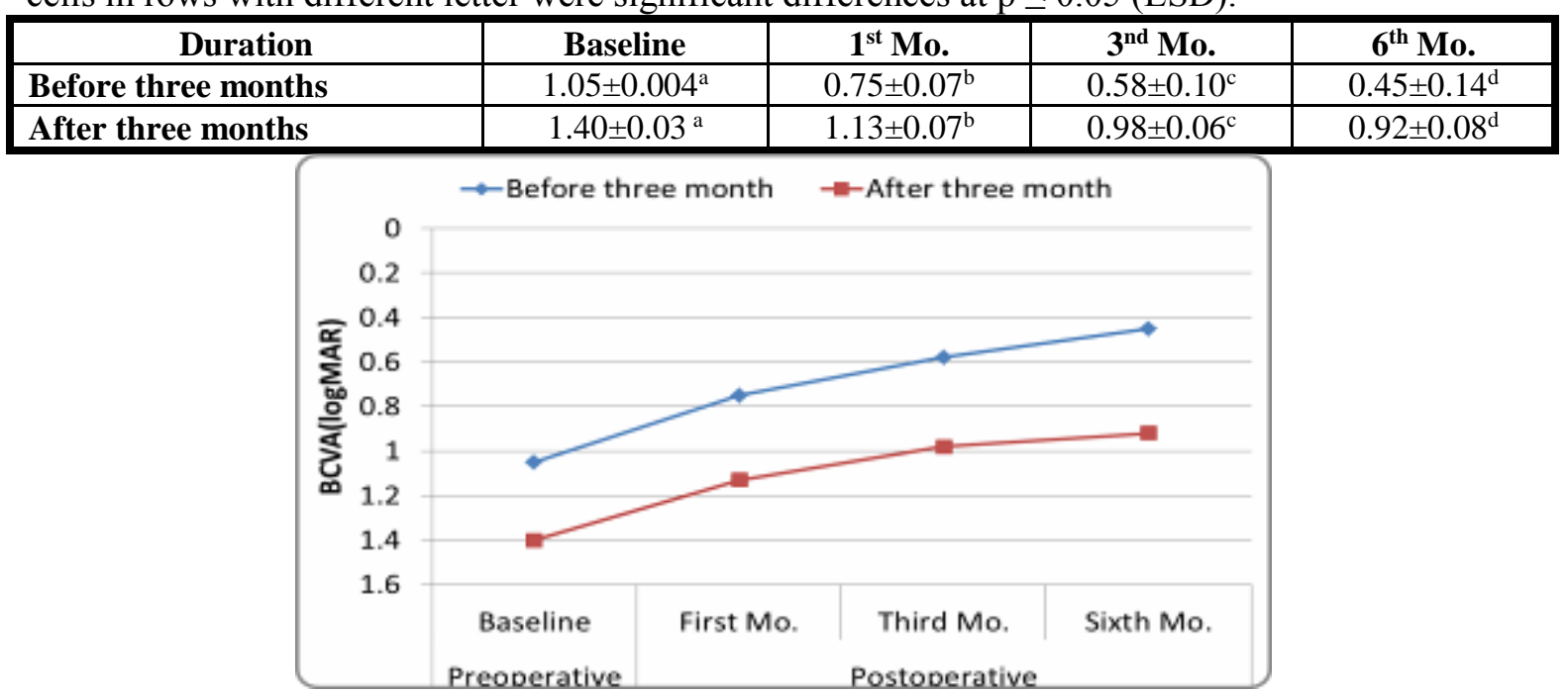

Figure (1): The mean BCVA at base line and after $1^{\text {st }}, 3^{\text {rd }}, 6^{\text {th }}$ months of aflibercept injection in patients with RVO.

The mean central macular thickness reduced from $485.57 \pm 71.51 \mu \mathrm{m}$ at baseline to $316.78 \pm 58.38 \mu \mathrm{m}(\mathrm{P} \leq 0.05)$ after 1 month, at the $3 \mathrm{rd}$ month reduced to $259.45 \pm 50.84 \mu \mathrm{m}(\mathrm{P} \leq 0.05)$ and by the end of 6th month reduced to $225.85 \pm 34.44 \mu \mathrm{m}(\mathrm{P} \leq 0.05)$ in those with $\mathrm{RVO} \leq 3$ months. Whereas, in those with RVO > 3 months the main CMT reduced from baseline $625.91 \pm 167.56 \mu \mathrm{m}$ to $395.07 \pm 98.89 \mu \mathrm{m}(\mathrm{P} \leq 0.05)$, 3rd month after injection reduced to $319.53 \pm 53.28 \mu \mathrm{m} \mathrm{P} \leq 0.05)$ and by the end of $6^{\text {th }}$ month reduced to $276.50 \pm 38.89 \mu \mathrm{m}(\mathrm{p} \leq 0.05)$ (table $2 \&$ figure 2$)$. The injection was well tolerated in all patients. No evidence of intra-operative or post-operative complications as retinal detachment, vitreous hemorrhage, or elevated intraocular pressure. prolonged delay in treatment is associated with less improvement in the visual acuity. Local hyperemia or subconjunctival hemorrhage may be noticed at the site of injection in some cases. 
Table (2): The mean central macular thickness at base line and after $1^{\text {st }}, 3^{\text {rd }}, 6^{\text {th }}$ months of aflipercept injection in patients with RVO.

*cells in rows with different letter were significant differences at $\mathrm{p} \leq 0.05$ (LSD).

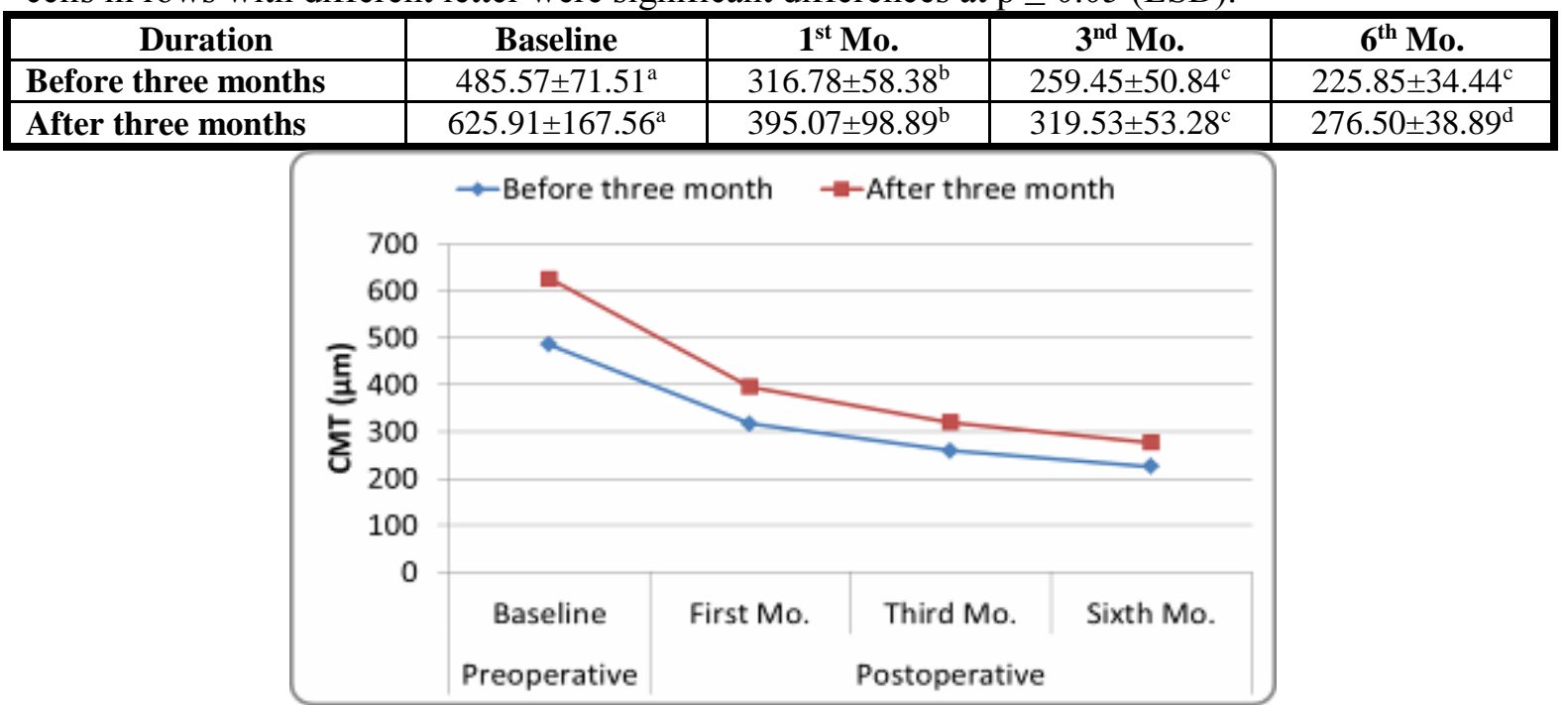

Figure (2): The mean central macular thickness at base line and after $1^{\text {st }}, 3^{\text {rd }}, 6^{\text {th }}$ months of aflibercept injection in patients with RVO.

Case No. 1

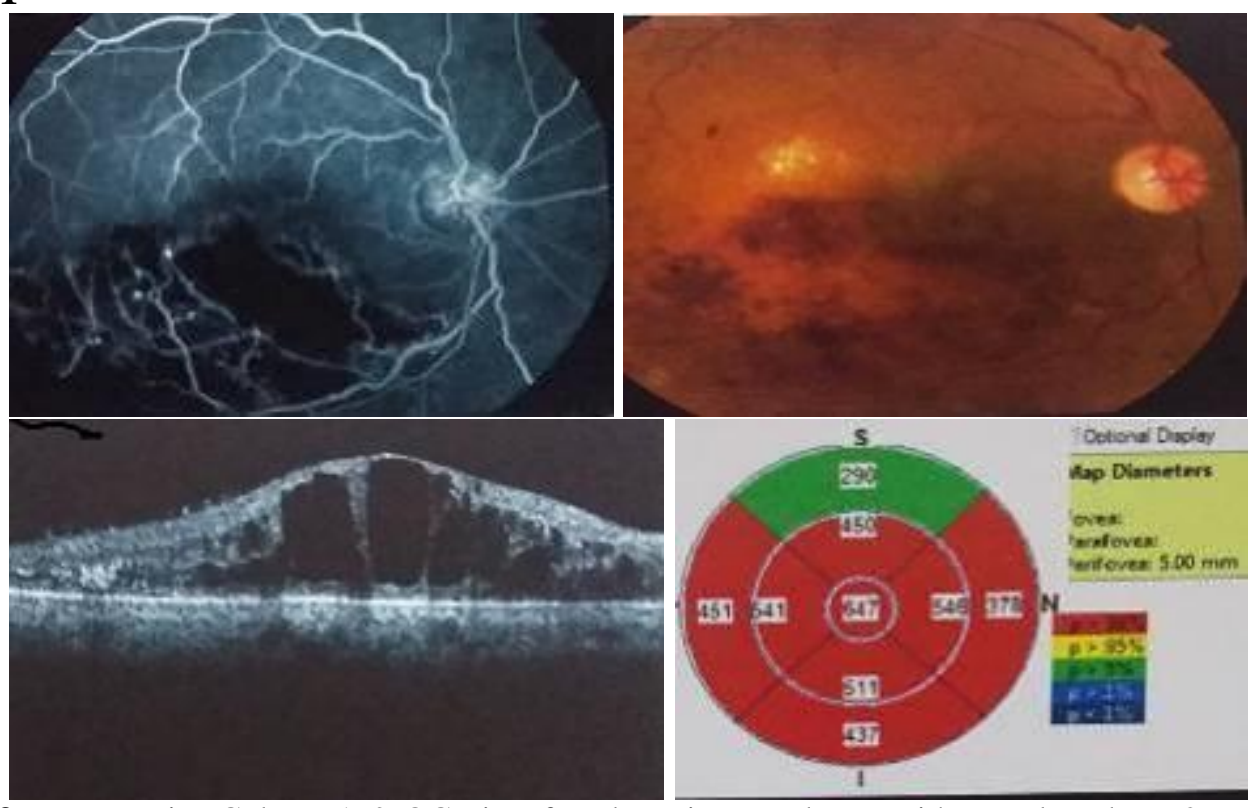

Figure 3: Preoperative Color, FA \& OCT in a female patient aged $69 \mathrm{y}_{\mathrm{s}}$ with macular edema $2^{\mathrm{ry}}$ to BRVO.
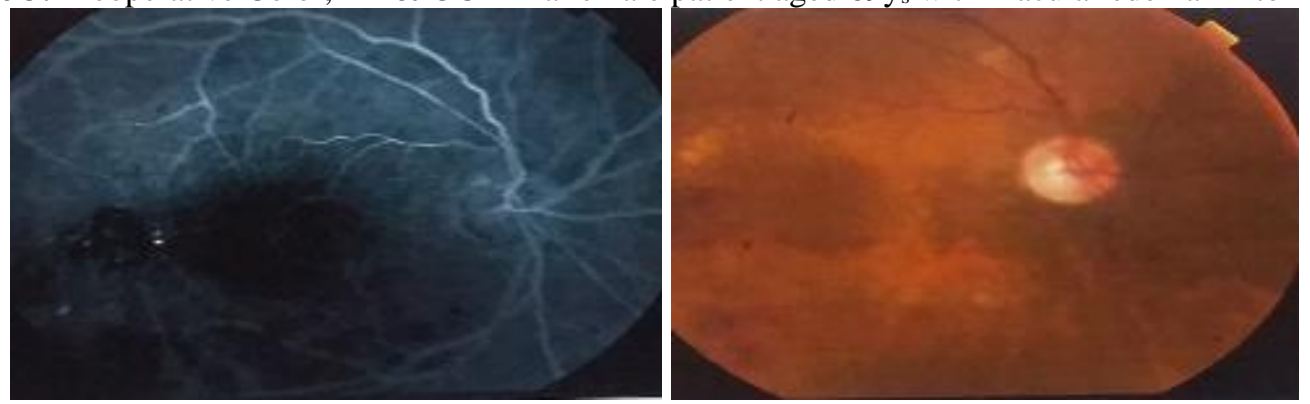

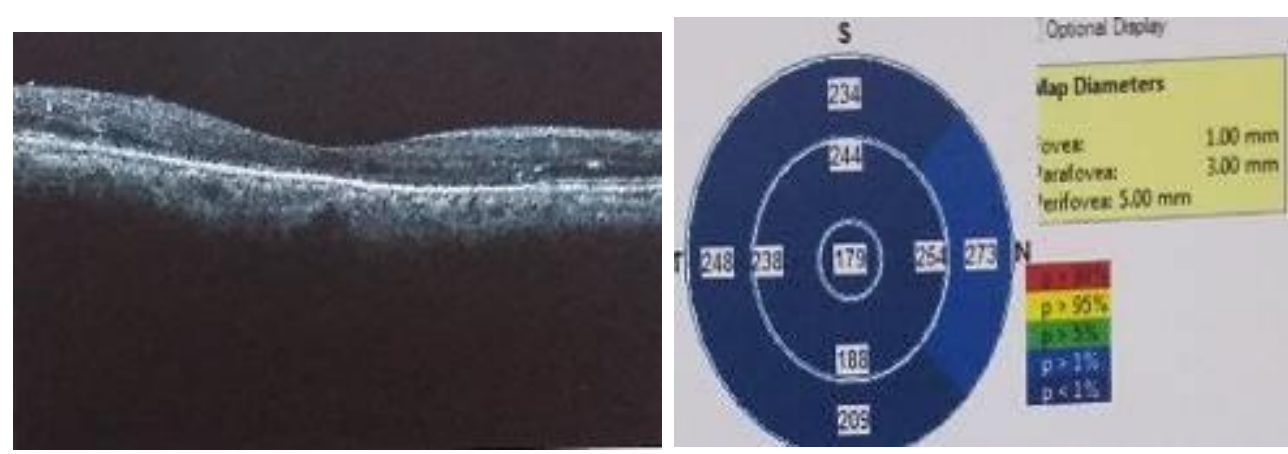

Figure 4: 6 months postoperative Color, FA \& OCT of the same patient revealed Complete resolution of the macular edema.

Case No. 2

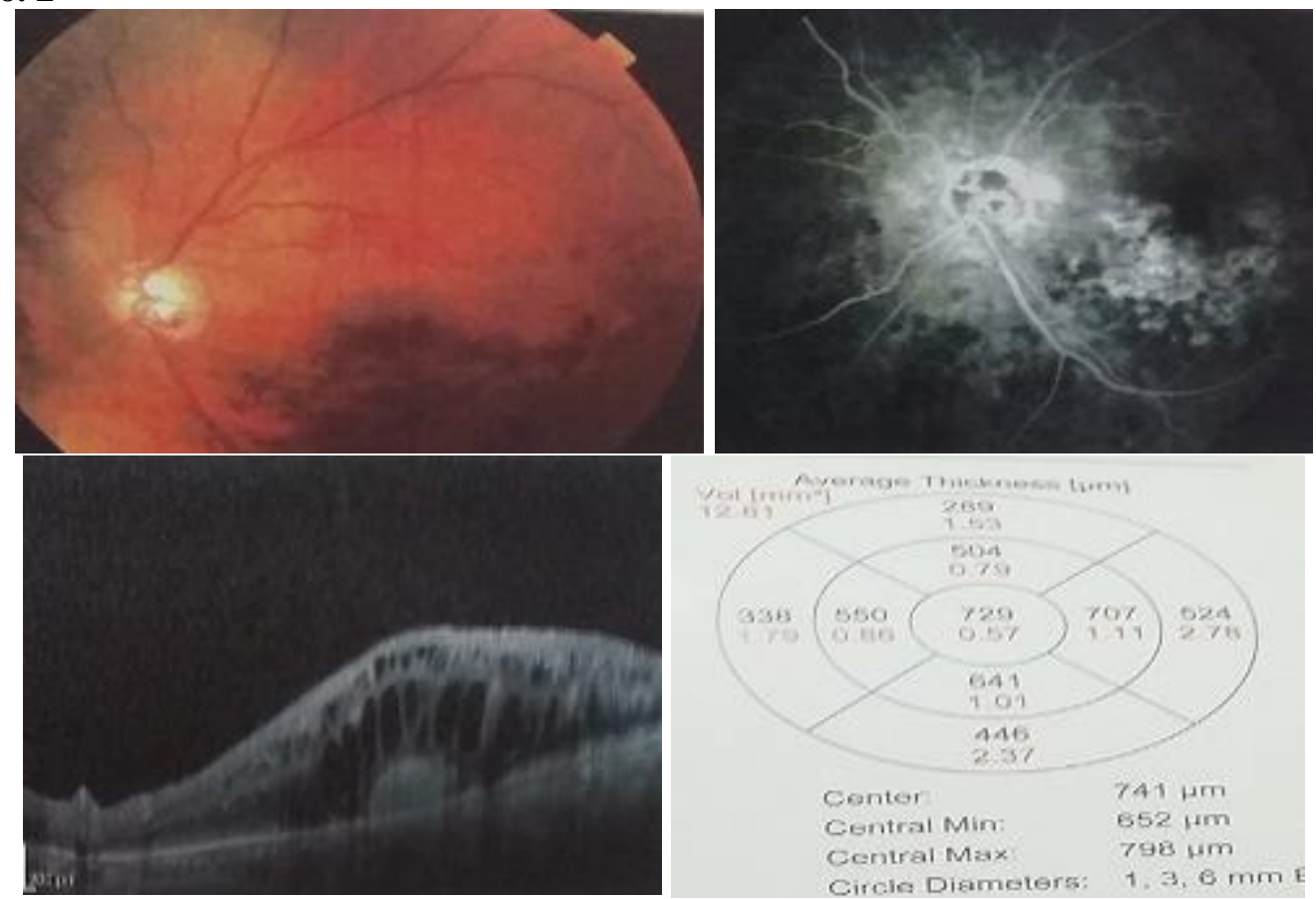

Figure 5: Preoperative Color, FA \& OCT in a male patient aged $71 \mathrm{y}_{\mathrm{s}}$ with macular edema $2^{\text {ry }}$ to BRVO.

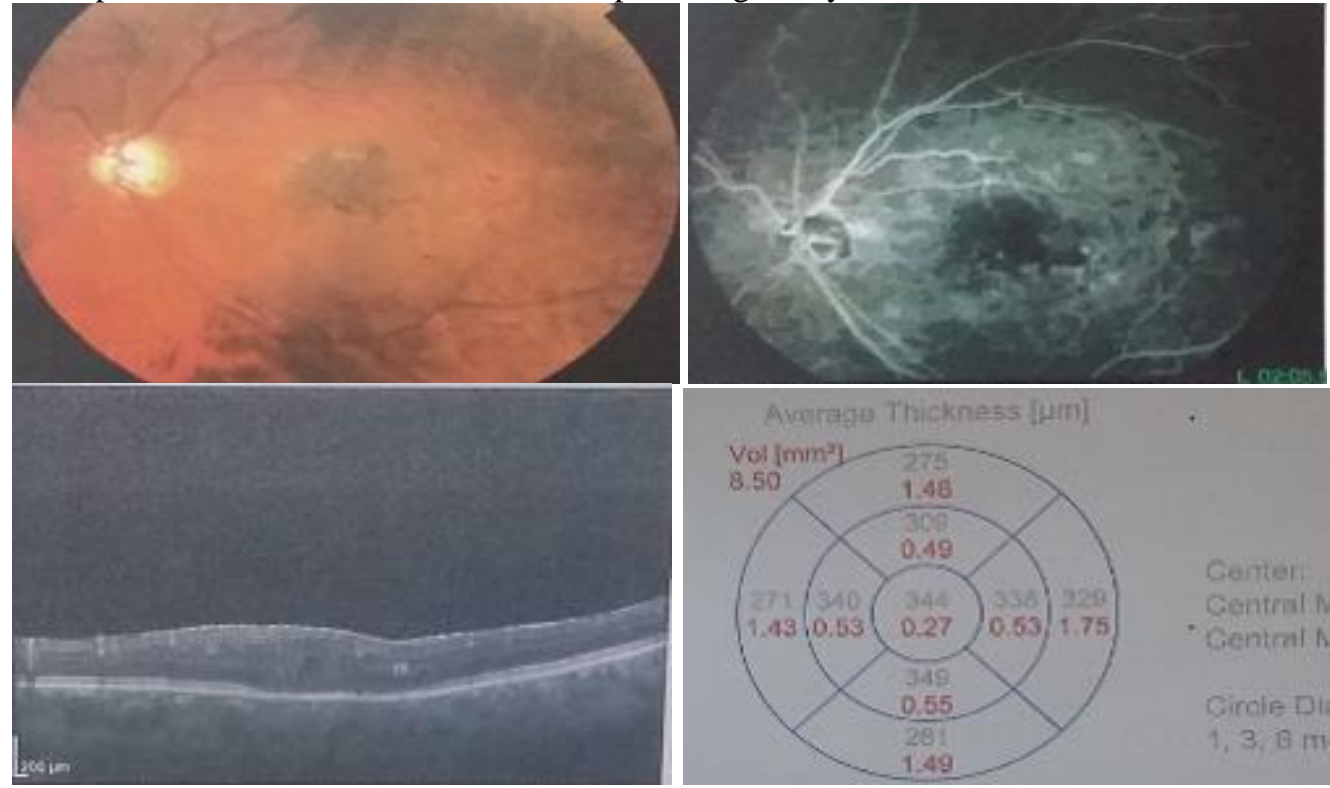

Figure 6: 6 months postoperative Color, FA \& OCT of the same patient revealed complete resolution of the macular edema. 


\section{DISCUSSION}

Retinal vein occlusions (RVOs) are the second most common retinal vascular diseases after diabetic retinopathy. RVO affects approximately one to two percent of adults over the age of $40^{[15,16]}$. While BRVO is four times more common than CRVO, however, CRVO is considered the most significant threat to vision [17]. The standard of care for macular edema secondary to branch retinal vein occlusion (BRVO) has been guided since 1984 by the findings of the Branch Vein Occlusion Study, which showed that macular photocoagulation was superior in improving visual acuity compared with observation ${ }^{[8]}$. The1995 Central Vein Occlusion Study (CVOS) concluded that grid laser treatment of macular edema was of no visual benefit despite the elimination of macular edema in treated eyes ${ }^{[9]}$. Since then, new pharmacologic agents have changed the treatment paradigm of macular edema secondary to RVO. There are 3 treatment options recently approved by the Food and Drug Administration (FDA) for treatment of macular edema secondary to RVO. These include a dexamethasone intravitreal implant (Ozurdex, Allergan), ranibizumab (Lucentis, Genentech), and aflibercept (Eylea, Regeneron). Intraocular injection of anti-VEGF has been shown to be a new promising treatment modality, which results in noticeable functional and anatomical improvement. Aflibercept is a decoy receptor fusion protein, composed of the second domain of human VEGF receptor 1 and the third domain of VEGF receptor 2, which are fused to the $\mathrm{Fc}$ domain of human IgG1. Aflibercept can downregulate VEGF-A, VEGF-B, and placental growth factor, which are synergistic for pathologic angiogenesis [18]. Aflibercept revealed superior anti-VEGF capability than bevacizumab in vitro. The binding affinity of VEGF for this drug is higher than for ranibizumab and bevacizumab, also it displays a prolonged VEGF inhibition in comparison with the other VEGF- antagonists in retinal pigment epithelium/choroid organ cultures ${ }^{[12,19]}$.

In a randomized controlled trial, aflibercept was compared with bevacizumab for treatment of diabetic macular edema. The authors concluded that aflibercept was more effective than bevacizumab for visual improvement in diabetic patients with poor baseline vision, but comparable efficacy in both pharmaceutical agents for better baseline vision. Both medications showed similar safety profiles and injection number during one-year follow-up ${ }^{[20]}$.

The Phase III registration trials demonstrated that intravitreal aflibercept is superior to standard-of-care for the treatment of macular edema due to BRVO and CRVO [21].

In our study, 60 eyes of 60 patients with macular edema due to RVO received a single intravitreal aflibercept injection revealed marked resolution of macular edema and improvement of visual acuity. Also, this study stated that improvement in vision and CMT depends on the duration of the disease, so greater improvement in vision and CMT noticed in those diagnosed and treated earlier than others and this coinciding with results of several studies which stated that the effect of antiVEGF agents on macular edema secondary to RVO occurs very soon after the initiation of treatment with improvement of both BCVA and CMT. However, improvement in visual acuity disproportionate to the amount of reduction in macular edema. Larger RVO trials suggest that even brief periods of under-treatment (as short as 6 months) may result in poorer long-term visual outcomes ${ }^{[14,21]}$. Also, our results support the results of other studies stated that RVO patients should be followed closely and regularly, so that recurrent edema can be treated promptly. Additional injections may be needed based on OCT findings especially in those with long term duration \& massive macular edema as single injection wasn't sufficient.

\section{CONCLUSION}

\section{Our study in the short term follow up period, concluded that:}

1- Intravitreal injection of aflibercept is more clinically effective and safe for treatment of macular edema $2^{\text {ry }}$ to RVOs and is generally well tolerated.

2- Good long-term anatomical \& functional outcomes could be obtained if the treatment started as early as possible.

\section{References}

1- Hahn P and Fekrat S(2012): Best practices for treatment of retinal vein occlusion. Current Opinion in Ophthalmology, 23(3): $175-181$. 2. The Royal College of Ophthalmologists (2015): Retinal ein Occlusion (RVO) Guidelines.https://http://www.rcophth.ac.uk/sta ndards- publications -research /clinicalguidelines /. 
3- Lee W, Kang M, Seong $M$ and Cho $H$ (2012): Comparison of aqueous concentrations of angiogenic and inflammatory cytokines in diabetic macular edema and macular edema due to branch retinal vein occlusion. British Journal of Ophthalmology, 96(11): 1426-1430.

4- Campochiaro PA, Hafiz G, Shah SM et al.(2008): Ranibizumab for macular edema due to retinal vein occlusions: implication of VEGF as a critical stimulator. Mol. Ther., 16:791-799. 5- Campochiaro PA, Bhisitkul RB, Shapiro $H$ and Rubio RG (2013): Vascular endothelia growth factor promotes progressive retinal nonperfusion in patients with retinal vein occlusion. Ophthalmology, 120:795-802.

6- Campochiaro PA, Clark WL, Boyer DS et al.(2015): Intravitreal aflibercept for macular edema following branch retinal vein occlusion: the 24- week results of the vibrant study. Ophthalmology,122:538-544.

7- McIntosh RL,Rogers SL,Lim L et al.(2010): Natural history of central retinal vein occlusion: an evidence-based systematic review. Ophthalmology, 117: 1113-1123.

8- The Branch Vein Occlusion Study Group (1984): Argon laser photocoagulation for macular edema in branch vein occlusion. Am. J. Ophthalmol., 98:271-282.

9- The Central Vein Occlusion Study Group (1995): Evaluation of grid pattern photocoagulation for macular edema in central vein occlusion. Ophthalmology, 102:1425-33.

10-Brown DM,Campochiaro W, Singh RP et al.(2010): Ranibizumab for macular edema following central retinal vein occlusion: sixmonth primary end point results of a phase III study. Ophthalmology, 117:1124-1133.

11- Holash J, Davis S, Papadopoulos $\mathrm{N}$ et al.(2002): VEGF-Trap: a VEGF blocker with potent antitumor effects. Proc. Natl. Acad. Sci.( U S A) ,99(17):11393-11398.

12- Papadopoulos N, Martin, Ruan $Q$ et al.(2012): Binding and neutralization of vascular endothelial growth factor (VEGF) and related ligands by VEGF Trap, ranibizumab and bevacizumab. Angiogenesis, 15(2):171-185.

13- Heier JS, Clark WL, Boyer DS et al.(2014): Intravitreal aflibercept injection for macular edema due to central retinal vein occlusion: two-year results from the Copernicus study. Ophthalmology, 121(17):1414-1420.

14- Ogura Y, Roider J, Korobelnik JF et al.(2014): Intravitreal aflibercept for macular edema secondary to central retinal vein occlusion: 18-month results of the phase 3
Galileo study. Am. J. Ophthalmol.,158 (5):1032-1038.

15- Orth DH and Patz A(1978): Retinal branch vein occlusion. Surv. Ophthalmol., 22 (6):357376.

16- Rogers S, McIntosh RL, Cheung $\mathbf{N}$ et al.(2010): The prevalence of retinal vein occlusion: pooled data from population studies from the United States, Europe, Asia and Australia. Ophthalmology, 117 (2) :313-319.

17- Wong TY and Scott IU (2010): Retinalvein occlusion. N. Engl. J. Med., 363:21352144.

18- Fauser S, Schwabecker V and Muether PS (2014): Suppression of intraocular vascular endothelial growth factor during aflibercept treatment of age-related macular degeneration. American Journal of Ophthalmology, 158(3): 532- 536.

19- Klettner A, Recber $M$ and Roider $J$ (2014): Comparison of the efficacy of aflibercep, ranibizumab and bevacizumab in an RPE/choroid organ culture. Graefe's Archive for Clinical and Experimental Ophthalmology, 252(10): 1593-1598.

20- Wells J A et al. (2015): Aflibercept, bevacizumab or ranibizumab for diabetic macular edema. The New England Journal of Medicine, 372(13): 1193-1203.

21- Campochiaro PA, Brown DM, Awh CC et al. (2011): Sustained benefits from ranibizumab for macular edema following central retinal vein occlusion: twelve-month outcomes of a phase III study. Ophthalmology, 118 (10):2041-2049. 